\title{
LOS DOMITII DE CONSABURA Y UNA NOTICIA DE FRONTINO ${ }^{1}$
}

\author{
THE DOMITII OF CONSABURA AND NEW INFORMATION BY FRONTIN
}

\author{
M. ${ }^{a}$ PILAR GONZÁLEZ-CONDE PUENTE \\ Universidad de Alicante
}

Escribía Plinio en su Historia Natural que los «consaburrenses» (N.H. 3, 25) vivían en una de las ciudades estipendiarias cuyos habitantes acudían a dirimir sus asuntos judiciales a Carthago Nova. Al referirse a ellos, el autor los incluía en un conjunto heterogéneo de ciudades pertenecientes, según él mismo explicaba, al menos a Celtíberos, Oretanos y Carpetanos. No hizo Plinio, sin embargo, ninguna precisión que permitiera incluir a los «consaburrenses» en alguna de estas unidades prerromanas que, por seguir la tradicional denominación romana, llamaremos «populi». Su intención era la mención de las más importantes ciudades del convento, clasificadas atendiendo a su condición jurídica $\mathrm{y}$, entre ellas, las más importantes entre las estipendiarias (stipendiariorum autem celeberrimi... Consaburrenses...).

La selección pliniana, como es sabido, respondía a la información que el autor tenía acerca de la promoción municipal de algunas ciudades y sin duda también a noticias antiguas no fácilmente contrastables, que convertían en «celeberrimi» unos núcleos cuyo verdadero protagonismo en la región no es fácilmente valorable. En algunos casos, con toda probabilidad, ese papel destacado se habría producido mucho tiempo atrás, en el marco de las guerras libradas por Roma en el territorio.

Los Consaburenses eran viejos conocidos de la administración romana por su aparente actitud en la guerra contra Sertorio. Una breve noticia del libro IV de los Stratagemata ${ }^{2}$, de dudosa atribución

1. Este trabajo se ha realizado en el marco del proyecto de investigación HAR2009-09104 (Los manuscritos de Ambrosio de Morales sobre las antigüedades de España: estudio y nueva edición), financiado por el Ministerio de Ciencia e Innovación del Gobierno de España.

2. Strat. 4, 5, 19. Para el debate sobre la autoría del libro IV de los Stratagemata, vid. Ch. E. Bennett (1980, XVII-XXIII), defendiendo que los tres primeros libros son de Frontino, mientras que el cuarto sería de otro autor. Se suma así a la tesis formulada antes por G. Gundermann (1888b, 315); vid. a Frontino, cuenta que los hispanos del oppidum de «Consabra» resistieron sin querer entregar la ciudad a Hirtuleyo. La trascendencia histórica que tuviera aquel episodio es desconocida para nosotros, porque los autores anteriores y posteriores que se refieren al desarrollo de la guerra sertoriana, o bien no lo mencionan o lo hacen sin nombrar el lugar exacto en el que ocurrió.

Desde Salustio y Tito Livio hasta Orosio, la tradición literaria romana recordó durante cuatro siglos el enfrentamiento entre Hirtuleyo y quien en aquel momento era gobernador de la Hispania citerior, L. Domitius Calvinus. La versión de Livio ( $P e-$ rioc. 90, 5-6) a propósito de que Domitius fue vencido por Hirtuleyo, y la mención de Salustio (Hist. 1, 96) sobre la preparación de la batalla, identificaban al derrotado como el procónsul de la Hispania citerior. El episodio se conservaba también en la biografía de Sertorio que muchos años después escribió Plutarco (Sert. 12, 3). Unos años más tarde, también Floro (2, $10,6)$ recogía el acontecimiento del enfrentamiento entre los dos personajes, una acción que aprovechaba el autor latino para hacer una reflexión sobre el carácter de la guerra sertoriana, convertida por él en guerra extranjera por la implicación de Lusitanos y Celtíberos.

En el siglo IV d.C., la derrota de Calvinus seguía presente en las fuentes históricas latinas, a través de la obra de Eutropio (Brev. 6, 1). Ahora, sin embargo, el acontecimiento era más dramático, porque el gobernador de la Citerior había muerto a manos de Hirtuleyo, un desenlace que no había aparecido hasta ese momento. Finalmente, era Orosio quien recordaba a Domitius para reseñar que había sido aniquilado junto

además su edición de la obra: id. 1888a, passim. Para la defensa de Frontino como autor también del libro IV, vid. entre las monografías dedicadas a esta parte de la obra: E. Fritze (1888); P. Esternaux (1899); y H.M. Connor (1921) con el estudio sintáctico que intenta demostrar su autoría. 
con su ejército a manos de Hirtuleyo ${ }^{3}$. La asepsia con la que se transmitía la victoria del bando sertoriano pudo modificarse en época tardía para recordar el final dramático para la causa romana que habría sido la muerte de Calvinus, si bien no es descartable una referencia anterior en Livio, a quien tanto debían Eutropio y Orosio (Pérez González, 1989, 9-10).

La localización de Consabura en Consuegra $(\text { Toledo })^{4}$, hace pensar inmediatamente en la cercanía de esta ciudad al teatro de operaciones del enfrentamiento entre Hirtuleyo y Calvino. Se asume generalmente que éste se habría producido junto al río Anas $^{5}$, aunque sólo la versión de Floro $(2,10,6)$ proporciona esta localización de forma clara, con la referencia al río. Es difícil determinar el lugar del enfrentamiento siguiendo exclusivamente las otras fuentes, especialmente en el caso de Plutarco (Sert. 12, 3), que hace una breve relación de diferentes batallas para recordar los avances sertorianos en diversos momentos y lugares.

3. Oros. 5, 23, 3:... Domitius ab Hirtuleio Sertorii duce cum exercitu oppressus est, que no indica necesariamente la muerte de Domitius. Es diferente la expresión de Eutropio (Brev. 6, 1), que sí se refiere a la desaparición física del personaje: A Sertorii duce Hirtuleio Domitius occisus est. Sin embargo, el texto de Orosio se ha puesto en relación con un fragmento de Salustio (I, $100-136 \mathrm{M}$ ), suponiendo que las palabras "formidine adtonitus» se refieren a la consternación del legado de Calvinus por la muerte de éste a manos de Hirtuleyo, lo que proporcionaría la primera mención de este suceso, si se acepta esta forma tan imprecisa: vid. R. Funari (1996, 269-270). Esta interpretación es posible por la lectura del Pap. Vindob. L. 117, tal como lo publicaron B. Bischoff y H. Boch (1979, 116-122). También para estos acontecimientos de la guerra sertoriana, vid. F. García Mora (1993, passim); L. Pérez Villatela (1994, passim); L. Amela (2002, 93 ss. y especialmente n. 84), con toda la bibliografía; G. Carrasco Serrano (2008, 30-31; n. 74, 76 y 78).

4. La bibliografía anterior sobre la ciudad de Consabura ha sido recogida ya ampliamente en los trabajos citados en este artículo, por lo que no se recopila aquí de nuevo. En este sentido pueden verse entre otros: J.C. Fernández-Layos de Mier (1983, passim); M. ${ }^{\text {a }}$ P. González-Conde (1987, 91-92; 198689, 53-54); J.J. Muñoz Villarreal (2000, 329-336; 2005a, 305-322; 2005b, 107-150), entre otros trabajos del autor.

5. P. Mcgushin (ed.) (1994, 170-171) dice que la batalla se localiza junto al río Anas en 4 fuentes: Livio, Plutarco, Floro y Orosio. Sin embargo, no todas ellas son explícitas acerca del lugar exacto, aunque la dinámica de los acontecimientos nos haga pensar que pueda tratarse del mismo episodio. En este sentido, en el marco de los sucesos de este período, Livio (Perioc. 90, 5-6) dice que Manlius y Domitius fueron vencidos por Hirtuleyo; Plutarco (Sert. 12, 3) menciona la victoria del general sertoriano entre otras desarrolladas en diferentes lugares durante esta guerra, lo que la descontextualiza; Orosio $(5,23,3)$ también alude al episodio, pero sin citar el lugar exacto. Solamente Floro $(2,10,6)$ hace una referencia explícita al Guadiana como lugar de la batalla. Sobre estos acontecimientos en el relato de Salustio, vid. R. Funari $(1996,226-227)$.
En este contexto impreciso, lleno de relatos que recordaban a Roma la gravedad de la acción sertoriana, destacan las noticias de los Stratagemata y de Floro, por ser las que proporcionan un referente geográfico para los acontecimientos que relatan, respectivamente la ciudad de Consabura y el río Anas. A pesar de la cercanía relativa entre ambos lugares, no se puede determinar la relación exacta entre estos sucesos, aunque es probable que exista al menos una cercanía temporal en el marco de los movimientos de Hirtuleyo que, proveniente de la Hispania ulterior, acabaría de penetrar en la Citerior, en donde se encontraría con las fuerzas de Calvinus. Los relatos sobre las acciones de Hirtuleyo desde su entrada en la Citerior y sus enfrentamientos con Domitius Calvinus daban cuenta de las victorias del bando sertoriano a través de quien era su mano derecha, que había puesto en una situación muy difícil a los gobernadores de la provincia (vid. n. 3).

La noticia del libro IV de los Stratagemata (4, 5, 19) sobre Consabura tenía, sin embargo, un sentido diferente. La ciudad había resistido de forma heroica el bloqueo de las tropas sertorianas y no se había entregado a Hirtuleyo. El autor recogía en su obra sobre la guerra algunas destacadas acciones que se habían desarrollado en suelo hispano, cuyo recorrido temporal abarcaba desde la segunda guerra púnica, pasando por el enfrentamiento contra Celtíberos y Lusitanos, hasta llegar a las luchas civiles de Sertorio y César. De todas ellas, la guerra sertoriana parece haber interesado especialmente al escritor ${ }^{6}$. En algunos de los fragmentos que aluden a estos años, cabe destacar una notable imprecisión geográfica, como queda patente en las tácticas militares seguidas por Sertorio para «cruzar un río» (Strat. 1, 5, 1) y por Hirtuleyo para escapar del enemigo al atravesar un paso «entre unas montañas» (Strat. 1, 5, 8). En otros casos, la referencia es a la guerra en Hispania de forma general, sin mencionar el lugar preciso en que se desarrollan los acontecimientos (como en Strat. 2, 1, 2-3). El autor parece haber recopilado noticias de la guerra sertoriana en Hispania, que le han llegado ya sin datos exactos sobre la localización geográfica o sobre el momento exacto en que se produjeron, con la única expresión «durante la guerra en Hispania». El objetivo de la obra

6. Los asuntos de Hispania se tratan ampliamente en los Stratagemata, especialmente en los libros 1, 2 y 4 . Dentro de ellos, hay un particular interés por la guerra sertoriana. Sin embargo, hay que tener en cuenta las posibles corrupciones en el texto, como ya apuntó G. Gundermann (1888b, 315), así como la llamada de atención de Ch. E. Bennett (1980, 315) sobre lo aleatorio de los fragmentos conservados, cuya transmisión estaría parcialmente ocasionada por las preferencias y el interés de los copistas medievales. Sobre la llegada del autor latino a la Edad Media, vid. M. ${ }^{\text {a }}$ F. del Barrio Vega (2006, 101-146) explicando cómo un manuscrito vaticano (Dicta et exempla ducum in bello; Pal. Lat. 1571), que se introdujo en la obra de Vegecio, era en realidad un resumen de los Stratagemata de Frontino. 
es la técnica militar y no está entre las prioridades del escritor la transmisión de la información exacta de los acontecimientos históricos. La excepción está en algunas anécdotas puntuales, en las que sí se menciona el lugar: una es el enfrentamiento entre Sertorio y Pompeyo junto a la ciudad de Lauro (Strat. 2, 5, 31); la otra es la resistencia de los habitantes de Consabura frente al acoso de Hirtuleyo (Strat. 4, 5, 19). La primera le sirve de ejemplo de una táctica de guerra; la segunda no sigue este objetivo general de la obra, sino que recuerda un acto heroico que respondía a la fidelidad de la ciudad para con la legalidad del estado romano.

La noticia sobre los Hispani de «Consabra» ${ }^{7}$ debe ser interpretada en el contexto propio de la ciudad de Roma y de la realidad del estado romano. Ésto plantea sin embargo dos grandes dificultades. De una parte, la discusión sobre la fecha de la composición de los Stratagemata, que impide dar con seguridad la oportunidad del momento histórico ${ }^{8}$, especialmente cuando hay un largo período en blanco en lo que se refiere al conocimiento de la vida y la carrera de Frontino desde su vuelta a Roma en 78 d.C. hasta el desempeño del cargo de curator aquarum para el que fue elegido por

7. En las fuentes literarias hay variaciones en el nombre de la ciudad. Plin., N.H. 3, 25 llama a sus habitantes Consaburrenses; Frontin. 4, 5, 19: Consabra; Ptol. 2, 6, 57: Condabora; It. Ant. 446, 4-7: Consabro; Rav. 4, 43-44: Consabron. Sobre la identificación de la ciudad con la Condabora celtibérica de Ptolomeo, vid. F. Fuidio $(1934,40)$ con las noticias anteriores sobre su identificación; G. Alföldy (1987, 52-54); M. ${ }^{\mathrm{a}}$ P. González-Conde (1992, 306; 1987, 46, 90-92); D. Urbina Martínez (1998, 198); J. Hurtado Aguña (2005, 22-23). En contra, planteando la duda de la identificación, vid. J. Montero Vítores $(1990,109)$ y J.J. Muñoz Villarreal (2005b, 111). La epigrafía no deja lugar a dudas sobre el nombre de la ciudad en época romana, ya que los tres individuos que especifican este origen lo hacen como «consaburensis»: Alföldy CIL $\mathrm{II}^{2} / 14,1131$ (= CIL II $4211=$ ILS 6936) de Tarragona, con la bibliografía anterior; Stylow CIL II $2 / 7,155$ (= CIL II 2166) de Montoro (Córdoba); R. González y G. Matilla (2007, 2829, Estela 1, fig. 3 y 4). Sobre la tessera de hospitalidad de Herrera de Pisuerga (Palencia), que nombraba a los «cusaburensis» y publicada por A. García y Bellido (1966, 149 s.; $c f$. ahora $A E 2002,785$ ), ya fue descartada su identificación con la Consabura localizada en la actual Consuegra (Toledo): M. ${ }^{\mathrm{a}}$ P. González-Conde (1987, 91-92).

8. Siguiendo la línea de la existencia de un pseudo-Frontino para el Libro IV, hay dos posiciones principales en el debate historiográfico: C. Wachsmuth $(1860,574)$ y E. Wölffin $(1875,72)$ sobre un posible autor tardío (siglos IV ó V d.C.); en contra, G. Gundermann (1888b, 315), que creyó que este libro se había escrito a comienzos del siglo II d.C., no mucho después de los tres primeros, por un autor cronológicamente cercano a Frontino; y M. Schanz $(1879,674)$, que se inclinó por la idea de que el autor era un contemporáneo del propio Frontino. En contra de la autoría de Frontino para todos los libros, L.C. Pérez Castro (1999, 39-47, especialmente 4647), citando la Tesis Doctoral de D. Schenk (1930, passim) para el estudio de las posibles similitudes entre Frontino y Vegecio. También sobre esta comparación, A.R. Menéndez Argüin $(2005,16$ ss.).
$\mathrm{Nerva}^{9}$. En segundo lugar, hay que tener en cuenta que esa única mención a «Consabra» está contenida en el libro IV, precisamente una parte de la obra que ha sido objeto de discusión, tanto en lo que se refiere a la fecha de realización como a su autoría.

El papel de Frontino en la alta política romana le sitúa en una posición cercana a los grupos de poder que entran en escena a la muerte de Domiciano, cuya prioridad consiste precisamente en demostrar que con ellos se inaugura un nuevo régimen político, basado en la libertas y en la concordia social. No es posible señalar si es su distancia política hacia el último de los flavios lo que explica el aparente silencio durante toda la etapa de gobierno de éste, aunque sí es apreciable su llegada a los cargos de responsabilidad a partir del cambio dinástico. Su cercanía a Nerva queda demostrada por su nombramiento como responsable de los acueductos de Roma, pero más importante es el papel que parece haber desempeñado en el cargo, como artífice de un nuevo modelo de gestión del agua que llegaba a la ciudad de Roma, tal y como dejó escrito en su obra «De aquis». Se convertía así en uno de los agentes principales de una nueva forma de hacer política, pero también en un transmisor de la nueva era en la que oficialmente entraba el funcionamiento del estado romano ${ }^{10}$.

Con el ascenso al poder de los Ulpios, Frontino se encontraba sin duda en una posición privilegiada, como demuestra su amistad con Plinio el Joven ${ }^{11}$, de quien es además protector y valedor para su entrada en el augurado. Pero la mejor muestra de su papel trascendental junto al nuevo monarca es el desempeño de su segundo y tercer consulado, respectivamente en los años 98 y 100, como colega del propio Trajano, tal y como su protegido se encargó de recordar en el Panegírico que leyó ante el Senado precisamente en esta última fecha (Plin., Paneg. 61 y 62). La conclusión tiene que ser necesariamente que Frontino estaba recogiendo una recompensa a un papel sin duda fundamental en el ascenso al poder de un miembro de la gens Ulpia. Esta cercanía al poder dota de una mayor trascendencia, si cabe, a su obra y a las noticias que de ella se derivan, tal y como ocurre con el dato sobre los habitantes de «Consabra».

9. $P I R^{2} 322$; entre la amplia bibliografía sobre la vida de Frontino, vid. a su editor, Ch. Bennett (1980, $1^{\mathrm{a}}$ ed. 1925, XI ss.). Para el papel que jugó como curator aquarum en la nueva política de Nerva, vid. D. Paniagua $(2006,231-234)$ y R. H. Rodgers (2009, 14-19). Vid. n. 10.

10. M. Peachin (2004, 114-127). El autor defiende que «De aquis» no es sólo un tratado o manual para los curatores aquarum, sino también un panfleto que transmite la idea de una reforma de la gestión del agua con la que se inauguraba la nueva era de gobierno de Nerva y Trajano.

11. Plin. Ep. 4, 8; 5, 1; 9, 19; A.-M. Guillemin $(2009,14-15$ y $53-56 ; 2003,112-114)$; A. N. Sherwin-White $(1966,272-$ 273,312 y $502-503$ ) 
La oportunidad de recordar todos estos datos en estas páginas, que quieren ser una reflexión sobre algunas cuestiones consaburenses, viene dada por la presencia de un ciudadano de este municipio en la propia Roma en algún momento del gobierno de Trajano. L. Domitius Dentonianus ${ }^{12}$ era un ciudadano oriundo del municipio de Consabura o muy vinculado a él, lo que le llevó a desempeñar allí los cargos públicos que rezan en la inscripción que se le dedicó en la colonia de Tarraco. Había accedido al orden ecuestre por una concesión imperial durante el reinado de Trajano, el mecanismo habitual que permitía la promoción de algunos individuos de las élites locales a este grupo social. Quizá ya como ecuestre, pudo acceder al cargo de juez de decuria, lo que le habría llevado seguramente a vivir en la capital del Imperio durante el desempeño de esta función, o al menos a realizar una estancia allí en determinados momentos del año judicial ${ }^{13}$. No era el único hispano de la provincia tarraconense que había sido elegido como juez de una de las cinco decurias, ni tampoco el único que procedía o residía en una ciudad modesta del interior de la provincia, como era Consabura (Alföldy, 1973, 20-21; Rodríguez Neila, 1978, 64-65). Los cargos desempeñados por el personaje aseguran su presencia en varios lugares a lo largo de su carrera pública; a saber, en Consabura, en Tarraco y en Roma.

La relación de Dentonianus con el municipio meseteño no ha sido totalmente aclarada ${ }^{14}$. El desempeño

12. Alföldy CIL II 2/14, 1131 (= CIL II $4211=I L S$ 6936), con la más reciente recopilación bibliográfica; G. Alföldy (1973, 34-35, 45 y 65 n. ${ }^{\text {o } 20) ; ~ i d . ~}\left(1975,148-149\right.$, n. $\left.^{\text {o }} 271\right)$. Tal y como explica G. Alföldy, la carrera de L. Domitius Dentonianus aparece en la inscripción de Tarraco en el orden de desempeño de los cargos, de manera que primero fue juez de decuria y accedió al rango ecuestre, para después ocupar los cargos municipales (duunvirado y flaminado perpetuo), un cargo militar ecuestre y, finalmente, el flaminado de la provincia Hispania citerior. Para el desempeño del flaminado provincial, el autor delimita la fecha entre 105 y 117 , lo que daría tiempo al personaje para ocupar los puestos anteriores, también durante el reinado de Trajano, pero antes de la muerte del príncipe, por la falta del término «divus». También en Tarraco conocemos una Domitia Fortunata, que es madre de un individuo de origo Toletanus (Alföldy CIL II $2 / 14,1056=$ II 4164).

13. S. Demougin $(1975,143-202)$; J. F. Rodríguez Neila (1978, n. 148) con la explicación de la clasificación de los jueces de decuria y sus obligaciones, así como los períodos de presencia obligada en Roma, lo que es interesante para Dentonianus.

14. Sobre la relación del personaje con la ciudad, vid. entre otros: G. Alföldy (1987, 52-54); M. ${ }^{\text {a }}$ P. González-Conde (1986-89, 61-62; 1987, 95-98); J.J. Muñoz Villarreal (2005a, 306-310). El hallazgo posterior de la inscripción de un consaburense en Archena (Murcia) adelanta la cronología estimada para la presencia familiar en el municipio: R. González y G. Matilla (2007, 28-29, Estela 1, fig. 3 y 4). Acerca del ascenso de algunas familias hispanas en época de Trajano, vid. J.-M. Roddaz $(2002,219)$. del duunvirado y el flaminado perpetuo le sitúa en un lugar destacado dentro de la élite consaburense, que seguramente tenía pocos ciudadanos que pudieran representar a su municipio en la capital provincial o incluso en la propia Roma. No hay constancia de la tribu a la que fueron adscritos aquellos consaburenses que se iban convirtiendo en ciudadanos romanos (Alföldy, 1987, 52-54; González-Conde 1986-89, 61-62), aunque no sería la Sergia, a la que pertenecía Dentonianus. Esta circunstancia obliga a pensar en una doble posibilidad: o bien L. Domitius Dentonianus tenía un origen foráneo, o se trataba de una concesión de ciudadanía individual. La presencia del gentilicio Domitius/a en el territorio está documentada, tanto en Consabura como en Caesarobriga, y en ambos casos corresponde a miembros de las élites locales. Resulta inevitable establecer una relación directa entre esta presencia onomástica y la evocación de noticias republicanas. Durante la guerra sertoriana, el gobernador de la citerior, L. Domitius Calvinus (Mangas, 1996, 41; Muñoz Villareal, 2005a, 309), había estado sin duda en la región y había luchado contra Hirtuleyo, quien le venció en nombre de la causa de Sertorio en algún lugar junto al Guadiana. Precisamente en el marco de esta etapa del conflicto sertoriano (vid. supra), se ubica también la mencionada noticia sobre la fidelidad y valentía de los Consaburenses, lo que podría llevar a establecer una fácil asociación entre un gobernador provincial y sus potenciales clientelas, que compartirían onomástica. Pero no es prudente en la actualidad ir más allá en esta conjetura para la que incluso hay argumentos que hacen dudar de esta relación onomástica. En este sentido, en la ciudad de Caesarobriga (Talavera de la Reina, Toledo) también hay Domitii entre su élite, como es el caso de la flaminica provincial y municipal Domitia Proculina (CIL II 895); sin embargo no podría alegarse este origen de época sertoriana en la onomástica porque la ciudad se encontraba en territorio de la provincia Lusitania, como puede apreciarse en el propio flaminado provincial de esta mujer, mientras que L. Domitius Calvinus era gobernador de la Citerior. Es probable que sus potenciales clientelas estuvieran dentro de los límites administrativos del territorio gobernado por él ${ }^{15}$. En sentido contrario, a favor de una posible relación con el gobernador Calvinus, estaría la cronología hoy cada vez más temprana del gentilicio en la ciudad.

15. La falta de precisión en las actuaciones de L. Domitius Calvinus, tal y como se presentan en las fuentes literarias, aconseja la prudencia. El caso de Consabura no es tan claro como el de otras ciudades en donde la presencia de un líder republicano queda mejor constatada. Un ejemplo es la ciudad narbonense de Aquae Sextiae, entre cuya élite están sobradamente documentados los Domitii como miembros de la élite local. Allí está clara la vinculación onomástica como resultado de una relación clientelar de época republicana, cuando L. Domitius Ahenobarbus estuvo en la región. Y. Burnand (1975, 235); F.J. García de Castro $(1997,115)$. 
El tiempo ha ido ampliando la presencia de Domitii en Consabura, aunque los testimonios de individuos portadores del nomen han sido hallados en todos los casos en lugares alejados del solar de la ciudad. A la inscripción de Dentonianus, hallada en la capital de la Citerior, en donde había desempeñado el cargo de flamen provincial, hay que unir actualmente al menos otros dos epígrafes. En la inscripción de Epora (Montoro, Córdoba) se señalaba el lugar de enterramiento de $Q$. Domitius Macer, también consaburense y liberto de $Q$ (uintus) ${ }^{16}$; con mucha probabilidad su patrono portaría el nomen Domitius, de quien lo habría tomado su antiguo siervo. Más difícil resulta decir si ambos compartían origo, aunque no es del todo descartable, lo que aportaría dos testimonios de Domitii consaburenses en este lugar de la Bética.

Hace unos años se publicó un nuevo testimonio de un consaburense enterrado fuera de su ciudad, que tenía el mismo gentilicio. Se trata de Q. Domitius Varinus $^{17}$, un consaburense cuya estela funeraria fue encontrada en Archena (Murcia) junto a otra similar que recordaba también a un foráneo («domo Valentia») llamado L. Publicius Daphnus (González y Matilla, 2007, 28 y 33-36, fig. 2 y 6). Aunque ambos soportes son estelas de cabecera semicircular y sin decoración, la mano que trazó el texto no es la misma, ni coinciden las fórmulas finales. Tal y como ya adelantaron los editores de ambas piezas, Daphnus pudo ser un liberto, condición que explicaría muy bien su tria nomina terminado en un cognomen de origen griego, que pudo ser antes su nombre de esclavo, adoptando quizá el praenomen y el nomen de su antiguo propietario $(L$. Publicius). Ambas lápidas funerarias compartían lugar de hallazgo, forma y estilo del soporte y ausencia de decoración; ambas correspondían a difuntos con tria nomina, sin referencia a la filiación ni a la tribu $\mathrm{y}$, al menos en uno de los casos, con un cognomen griego; finalmente, ambas pueden datarse en el siglo I d.C. (González y Matilla, 2007, 32). Por todo ello, existe la posibilidad de que $Q$. Domitius Varinus fuera también un liberto, que habría asumido el nomen de su patrono, como cabría esperar. Su posible relación servil con un Domitius, su onomástica y su origo

16. Stylow CIL II $2 / 7,155$ (= CIL II 2166) con la bibliografía anterior. El cognomen se documenta en otra inscripción de la misma procedencia, parcialmente leída y hoy perdida: Stylow CIL II $2 / 7,166$ (quizá también en CIL II ${ }^{2} / 7,165$ ). Sobre la referencia de la inscripción en manuscritos de la Real Academia de la Historia, vid. J.M. Abascal y R. Cebrián (2005, 77-78, 412, 322): manuscritos RAH-9-7379-27, RAH-7378-21a, y RAH-7379-20. Sobre los posibles motivos de su presencia allí, vid. J.J. Muñoz Villarreal (2005a, 308).

17. R. González y G. Matilla (2007, 28-29, Estela 1, fig. 3 y 4); J. Andreu Pintado $(2008,366)$ ya la incluía, aunque todavía como inédita; G. Carrasco Serrano (2008, 242, n. 83) ya mostraba el interés de esta inscripción para la sociedad consaburense. hacen especialmente interesante al personaje en estas páginas, y plantean la opción de que su patrono tuviera su misma origo, lo que aportaría la noticia sobre dos Domitii consaburenses a través de la inscripción de Archena. No puede asegurarse con total certeza esta coincidencia de origen, aunque es una opción a considerar.

Los motivos por los que Q. Domitius Varinus estaba en Archena, en donde encontró la muerte, no son conocidos. Sin embargo, la posible relación de la élite consaburense con la costa mediterránea de la península Ibérica ya fue planteada por G. Alföldy (1987, 5354), quien observó que la tribu Sergia de Dentonianus no debía ser la propia de Consabura y que quizá habría que pensar en una colonia de la costa mediterránea. Es posible que la dispersión de estos libertos de Domitii consaburenses tenga una relación directa con los intereses económicos de sus patronos en diferentes lugares de Hispania.

A la luz de la información epigráfica, en la actualidad se pueden hacer varias afirmaciones sobre los Domitii consaburenses. En primer lugar, bajo ese gentilicio encontramos a miembros de la élite consaburense y a sus libertos. Las inscripciones nos dan los nombres de algunos de sus libertos, aunque eso requiere que la origo declarada por ellos sea la misma que la de sus patronos (lo que es altamente probable en este caso) y que los dos testimonios foráneos sean libertos (en el caso del individuo de Epora lo es con seguridad; en el caso del de Archena, con mucha probabilidad). Los intereses familiares les llevan en ocasiones fuera de su ciudad de origen, en un caso para iniciar una brillante carrera pública y en los otros por motivos que desconocemos; es posible que la presencia de sus libertos en otros lugares estuviera relacionada con los asuntos económicos de sus antiguos amos. En la actualidad no se puede conocer su primera presencia en la ciudad ni su raigambre en la misma, aunque la adscripción de uno de sus miembros a la tribu Sergia es un elemento a tener en cuenta. En cualquier caso, el testimonio de Archena nos remonta en el tiempo hasta unas fechas con las que hasta ahora no contábamos para la presencia del gentilicio en la ciudad, documentándolos allí al menos desde la primera mitad del siglo I d.C. hasta algún momento del reinado de Trajano (vid. n. 12).

El nombre de la ciudad de Consabura pudo conocerse fuera de su territorio ya desde época julio-claudia gracias a la presencia de algunos de sus habitantes en lugares alejados, como es el caso de Q. Domitius Varinus en Archena. A lo largo de ese mismo siglo I d.C., también en la Bética, en donde estaban presentes en la ciudad de Epora. Sin embargo, la popularidad de esa pequeña ciudad del interior de la meseta pudo dar un salto cualitativo cuando uno de sus ciudadanos viajó a Roma para tomar posesión como juez de decuria, consiguiendo además ser elevado por el propio Trajano al rango ecuestre.

Como hemos dicho, por esas fechas estaba también en Roma Sextus Iulius Frontinus (PIR 322$)$ uno de 
los senadores con más influencia política en el «nuevo régimen» que pretendían haber instaurado Nerva y Trajano, tan poderoso como para haber desempeñado el consulado en dos momentos clave como los años 98 y 100 d.C. (vid. n. 9). Parece que Frontino escribía por entonces sus Stratagemata, una obra en la que prestó no poca atención a Hispania y especialmente a la guerra sertoriana desarrollada en el solar peninsular. La transmisión de su obra, conservada en forma de cuatro libros, proporcionaba la primera noticia que nos ha llegado sobre la heroica actitud de los habitantes de la ciudad de Consabura durante la guerra sertoriana y sobre su fidelidad a la causa del estado romano. La opinión que, de forma más o menos general, atribuye la autoría del libro IV (y por tanto de la noticia sobre Consabra) a un pseudo-Frontino, parece dejar sin conexión estos acontecimientos. Sin embargo, la coincidencia (o cercanía temporal) de un consaburense en Roma con la noticia sobre la ciudad en los Stratagemata debe al menos ponerse en relación.

La noticia sobre la fidelidad de Consabura a la causa del estado romano pudo llegar en esta época a Roma, quizá incluso de la mano de un consaburense como L. Domitius Dentonianus. Si la noticia ya era conocida, entonces quizá la presencia de este ecuestre volvía a ponerla en valor. En cualquiera de los dos casos, llama la atención que la denominación sea «Consabra» en lugar de su nombre latino correcto (Consabura), que sería el que habría dado un consaburense. La explicación bien puede ser una corrupción posterior en el texto, lo que habría dado lugar a una denominación que se conserva casi idéntica en época tardía en los itinerarios que mencionan esta mansio $^{18}$. Habría sido una pequeña contribución provincial a la grandeza del imperio de Nerva y Trajano, que era por cierto el contexto en el que Dentonianus había conseguido los máximos honores. No es imposible por tanto que Frontino o alguien del entorno imperial llegara a conocerla, con independencia de la autoría y datación que se conceda al conjunto del libro IV de su obra sobre la guerra. La información contenida en el libro IV de los Stratagemata, o al menos una parte de ella, pudo tener su origen en época del propio Frontino, siendo por lo tanto el fruto de los conocimientos y de los contactos del autor. Un buen ejemplo es la citada noticia sobre los Consaburenses. Esta circunstancia no excluye la posibilidad de que el libro, en su forma actual, sea una elaboración posterior.

La utilidad de la difusión de esta noticia de Frontino en época trajanea tenía una doble utilidad para los Domitii del municipio hispano; de una parte el episodio contribuía a poner a la ciudad en el mapa de los aliados históricos de Roma; de otra, favorecía los intereses de

18. Para Plinio (N.H. 3, 25), sus habitantes son los Consaburrenses. En Ptolomeo (II, 6, 57) la ciudad es Condabora. En los Itinerarios tardíos: Consabro (It. Ant. 446, 4-7) y Consabron (Rav. 4, 43-44).
Dentonianus y su familia, quienes sin duda tenían ya desde la centuria anterior asuntos económicos dentro y fuera de Consabura.

\author{
Profa. Dra. M. ${ }^{\text {a }}$ Pilar González-Conde Puente \\ Área de Historia Antigua \\ Dpto. Prehistoria, Arqueología, \\ Historia Antigua, Fil. Griega y Fil. Latina \\ Universidad de Alicante \\ 03080 Alicante \\ pilar.gonzalez@ua.es
}

\section{BIBLIOGRAFÍA}

ABASCAL, J.M. y CEBRIÁN, R., 2005: Manuscritos sobre antigüedades, Madrid.

ABASCAL, J.M. y GONZÁLEZ-CONDE, M. ${ }^{a}$ P., 2007: «Carpetania: argumentos para una definición del territorio en época romana», en Estudios sobre la Edad del Hierro en la Carpetania, vol. II, Zona Arqueológica 10, 291-301.

ALFÖLDY, G., 1973: Flamines provinciae Hispaniae citerioris, Anejos de Archivo Español de Arqueología 6, Madrid.

ALFÖLDY, G., 1975: Die römischen Inschriften von Tarraco. Berlin.

ALFÖLDY, G., 1987: Römisches Städtewesen auf der neukastilischen Hochebene. Ein Testfall für die Romanisierung, Heidelberg.

AMELA VALVERDE, L., 2002: Las clientelas de Cneo Pompeyo Magno en Hispania, Barcelona.

ANDREU PINTADO, J., 2008: «Sentimiento y orgullo cívico en Hispania: en torno a las menciones de origo en la Hispania Citerior», Gerión, 26:1, 349-378.

BARRIO VEGA, M. ${ }^{a}$ F. del, 2006: «Un resumen inédito de los Stratagemata de Frontino como fuente del libro XII del De Preconiis Hispanie de Gil de Zamora», Cuadernos de Filología Clásica. Estudios Latinos, 26.1, 101-146.

BENNETT, Ch. E. (ed.), 1980: Frontinus. The Stratagems and the Aqueducts of Rome, Cambridge-Massachusetts, The Loeb Classical Library ( $1^{\text {a }}$ ed. 1925).

BISCHOFF, B. y BLOCH, H., 1979: «Das Wiener Fr. der Hist. des Sallust (P. Vindob. L 117)», Wiener Studien, 13, 116-129.

BURNAND, Y., 1975: Domitii Aquenses. Une famille de chevaliers romains de la région d'Aix-en-Provence. Mausolée et domaine, Revue Archéologique de Narbonnaise, Supplément 5, Paris.

CARRASCO SERRANO, G., 2008: «La intervención romana en Castilla-La Mancha: la anexión del territorio», en G. CARRASCO SERRANO (ed.), La romanización en el territorio de Castilla-La Mancha, Cuenca.

CONNOR, H.M., 1921: A Study of the Syntax of the Stratagemata of Frontinus, Diss, Ithaca.

DEMOUGIN, S., 1975: «Les juges des cinq décuries originaires de l'Italie», Ancient Society, 6, 143-202.

ESTERNAUX, P., 1899: Die Komposition von Frontinus Stratagemata, Berlin. 
FERNÁNDEZ LAYOS DE MIER, J.C., 1983: Historia de Consuegra, Toledo.

FRITZE, E., 1888: De Iuli Frontini Stratagematon Libro IV, Diss, Halle.

FUIDIO, F., 1934: Carpetania romana, Madrid.

FUNARI, R., 1996: C. Sallusti Crispi Historiarum Fragmenta, 2 vols., Amsterdam.

GARCÍA Y BELLIDO, A., 1966: «Tessera hospitalis del año 14 de la Era hallada en Herrera de Pisuerga (Palencia)», Boletín de la Real Academia de la Historia, 159, 149-166.

GARCÍA DE CASTRO, F.J., 1997: «Élites municipales a través de las fuentes epigráficas. El ejemplo de Aquae Sextiae», Espacio, Tiempo y Forma, serie II, t. 10, 109-119.

GARCÍA MORA, F., 1993: «Sertorio frente a Metelo (7978 a.C.)», en II Congreso peninsular de História antiga, 375-398, Coimbra.

GONZÁLEZ FERNÁNDEZ, R. y MATILLA SÉIQUER, G., 2007: «Dos nuevas estelas funerarias con mención de origo procedentes del balneario de Archena (Murcia)», en Faventia 29/2, 21-36.

GONZÁLEZ-CONDE PUENTE, M. ${ }^{a}$ P., 1987: Romanidad $e$ indigenismo en Carpetania, Alicante.

GONZÁLEZ-CONDE PUENTE, M. ${ }^{a}$ P., 1986-89: «L. Domitius Dentonianus y la promoción jurídica de Consabura», Hispania Antiqua, 13, 53-70.

GONZÁLEZ-CONDE PUENTE, M. ${ }^{a}$ P., 1992: «Los pueblos prerromanos de la meseta sur», en M. ALMAGRO GORBEA y G. RUIZ ZAPATERO (eds.), Paleoetnología de la Península Ibérica, Complutum, 2-3, 299-309.

GUILlEMIN, A.-M. (ed.), 2009: Pline le Jeune. Lettres. Livres IV-VI, Paris.

GUILlEMIN, A.-M., (ed.), 2003: Pline le Jeune. Correspondance. Livres VII-IX (sixième édition revue et corrigé par Hubert Zehnacker). Paris.

GUNDERMANN, G., 1988a: Iuli Frontini Stratagematon Libri quattuor, Leipzig.

GUNDERMANN, G., 1988b: «Quaestiones de Iuli Frontini Stratagematon Libris», en Fleckeis Jahrbuch Supplementbd. 16, 315ss.

HURTADO AGUÑA, J., 2005: Los territorios septentrionales del Conventus Carthaginensis durante el Imperio romano, Estudio de la romanización de Carpetania. Oxford, BAR International Series 1415.

MANGAS, J., 1996: Aldea y ciudad en la antigüedad hispana, Madrid.

MCGUSHIN, P. (ed.), 1994: Sallust, The Histories, volume I, Books I-II, New York.

MENÉNDEZ ARGÜIN, A.R. (ed.), 2005: Flavio Vegecio Renato: el arte de la guerra romana, Madrid.

MONTERO VÍTORES, J., 1990: «La Carpetania en Ptolomeo», en Toledo y la Carpetania en la edad antigua, 97-111, Toledo.
MUÑOZ VILLARREAL, J.J., 2001: «Consuegra: ciudad y territorio», en L. HERNÁNDEZ GUERRA, L. SAGREDO y J.M. a SOLANA (eds.), Actas del I Congreso Internacional de Historia Antigua «La Península Ibérica hace 2000 años», 329-336, Valladolid.

MUÑOZ VILLARREAL, J.J., 2005a: «Algunas consideraciones sobre la inscripción CIL II 4211 y el Municipium Consaburensis», en Actas del II Congreso Internacional de Historia Antigua «La Hispania de los Antoninos (98180)», 305-322, Valladolid.

MUÑOZ VILLARREAL, J.J., 2005b: «Consabura: de oppidum a municipio romano», Hispania Antiqua, 29, 107-150.

PANIAGUA AGUILAR, D., 2006: El panorama literario técnico-científico en Roma (siglos I-II d.C.) «Et docere et delectare», Salamanca.

PEACHIN, M., 2004: Frontinus and the curae of the curator aquarum, HABES 39, Stuttgart.

PÉREZ CASTRO, L.C., 1999: «Acerca de Frontino y ¿sus? Stratagemata», Emerita, 67.1, 39-47.

PÉREZ GONZÁlEZ, M. (ed.), 1989: Tito Livio. Los orígenes de Roma, Madrid, Akal Clásica, Clásicos Latinos $\mathrm{n}^{\mathrm{o}} 24$.

PÉREZ VILATELA, L., 1996: «La campaña de Sertorio en Carpetania y Celtiberia en 77 a. de J.C. según Plutarco», en J.A. FERNÁNDEZ DELGADO y F. PORDOMINGO PARDO (eds.), Estudios sobre Plutarco: aspectos formales, 369-380, Salamanca.

RODDAZ, J.-M., 2002: «Hispania pacata: 1'Empereur et les Espagnes aux deux premiers siècles de l'Empire», en Hispania terris omnibus felicior. Premesse ed esiti di un processo di integrazione, Atti del convegno internazionale, Cividale del Friuli, 2001 (a cura di Gianpaolo Urso), 201-223, Pisa.

RODGERS, R. H., 2009: Frontinus: De Aquaeductu Urbis Romae, Cambridge- New York-Melbourne.

RODRÍGUEZ NEILA, J. F., 1978: «Los jueces de las Cinco Decurias oriundos de la Hispania romana», Hispania Antiqua, 8, 17-65.

SCHANZ, M., 1889: «Zu Frontins Kriegslisten», Philologus, 48, 674-680.

SCHENK, D., 1930: Flavius Vegetius Renatus. Die Quellen der Epitoma Rei Militaris, Leipzig.

SHERWIN-WHITE, A. N., 1966: The Letters of Pliny, Oxford.

URBINA MARTÍNEZ, D., 1998: «La Carpetania romana y los carpetanos indígenas: tribu, etnia, nación o el país de los escarpes», Gerión, 16, 183-208.

WACHSMUTH, C., 1860: «Über die Unächtheit des vierten Buchs der Frontischen Stratagemata», Rheinisches $\mathrm{Mu}-$ seum, 15, 574-583.

WÖLFFIN, E., 1875: «Frontins Kriegslisten», Hermes, 9, 72-92 